\title{
Correlation of bleeding pattern with endometrial histopathologic results in perimenopausal women with abnormal uterine bleeding
}

\author{
Zehra Yilmaz ${ }^{1}$, Elif Akkas Yilmaz ${ }^{1}$, Bulent Cakmak ${ }^{2 *}$, Ismail Burak Gultekin ${ }^{1}$, \\ Mehmet Fatih Karsli ${ }^{1}$, Yasemin Cekmez ${ }^{1}$, Osman Fadil Kara ${ }^{1}$, Tuncay Kucukozkan ${ }^{1}$
}

\begin{abstract}
${ }^{1}$ Department of Obstetrics \& Gynecology, Dr. Sami Ulus Women's and Children's Health Teaching and Research Hospital, Sihhiye-06200, Ankara, Turkey

${ }^{2}$ Department of Obstetrics \& Gynecology, School of Medicine, Gaziosmanpasa University, Merkez-60100, Tokat, Turkey
\end{abstract}

Received: 07 March 2015

Accepted: 19 April 2015

*Correspondence:

Dr. Bulent Cakmak,

E-mail: drbulentcakmak@hotmail.com

Copyright: $\odot$ the author(s), publisher and licensee Medip Academy. This is an open-access article distributed under the terms of the Creative Commons Attribution Non-Commercial License, which permits unrestricted non-commercial use, distribution, and reproduction in any medium, provided the original work is properly cited.

\begin{abstract}
Background: Abnormal Uterine Bleeding (AUB) is referred as bleeding outside of normal menstruation pattern and it is the most common gynecological problem for women of all ages. This study was evaluated the correlation of menstrual bleeding patterns and endometrial histopathological findings in perimenopausal women.

Methods: This study was done on perimenopausal aged women presented with AUB for the last 6 months at a gynecology clinic of a tertiary medical center. Only the patients with isolated endometrial causes of AUB were selected for study. A total of 313 cases were included in the study. Abnormal bleeding patterns of the patients were recorded and endometrial sampling was performed to all women. AUB was classified as menorrhagia, metrorrhagia, menometrorrhagia, polymenorrhea, intermenstrual bleeding, and histopathological findings were classified as Proliferative Endometrium (PE), Secretory Endometrium (SE), Disordered Proliferative Pattern (DPP), Endometrial Polyp (EP), Chronic Endometritis (CE), Endometrial Hyperplasia (EH), and Endometrial Adenocarcinoma (CA).

Results: The most common bleeding pattern was menorrhagia (45.0\%) and the most common histopathological finding was $\mathrm{PE}+\mathrm{SE}(52.0 \%)$ in our study. $\mathrm{PE}+\mathrm{SE}$ and endometrial hyperplasia without atypia were found more common in menorrhagia group. The most histopathological findings were found $\mathrm{PE}+\mathrm{SE}$ in menometrorrhagia and polymenorrhea group $(\mathrm{P}<0.001)$. Although $\mathrm{EP}$ and $\mathrm{CE}$ were observed more common in intermenstrual bleeding group $(\mathrm{P}<0.001)$, there were no statistically significant difference in endometrial histopathological findings in metrorrhagia group $(\mathrm{P}>0.05)$.

Conclusions: We concluded that although menometrorrhagia and polymenorrhea were significantly more associated with PE+SE, intermenstrual bleeding was significantly more associated with EP and CE. It is noteworthy that endometrial hyperplasia without atypia is significantly higher in patients with menorrhagia which is the most common abnormal bleeding pattern in perimenopausal aged women.
\end{abstract}

Keywords: Abnormal uterine bleeding, Perimenopausal, Endometrium, Histopathology

\section{INTRODUCTION}

Any bleeding outside of normal menstruation pattern with excessive duration, frequency, and amount is referred as Abnormal Uterine Bleeding (AUB) and it is the most common gynecological problem for women of all ages. It occurs in 9-14\% of women and accounts for one-third of all outpatient gynecologic visits, two thirds of all hysterectomies. ${ }^{1-3}$ AUB can be caused by either 
organic (endometrial polyps, hyperplasia, myomas, atrophy, and cancer) or non-organic etiologies. ${ }^{4}$

Endometrial pathologies as polyps, submucous myomas, endometrial hyperplasia, and endometrial carcinoma must be suspected and evaluation of endometrium is necessary in AUB in perimenopausal women. ${ }^{1}$ Endometrial biopsy or Dilatation and Curettage (D\&C) is a safe and effective technique for evaluation of AUB and for diagnosis of endometrial pathologies such as infections, polyps, endometrial hyperplasia and endometrial carcinoma. ${ }^{5}$ AUB is a general term and can have a broad range of clinical features such as oligomenorrhea, polymenorrhea, menorrhagia, menometrorrhagia, metrorrhagia, mid-cycle spotting, and abnormal acute vaginal bleeding and the patient can come to the clinic with a variety of abnormal bleeding pattern. ${ }^{6,7}$

We aimed in this study to assess the frequency of different histopathological findings obtained from endometrial biopsy specimen among perimenopausal women complaining AUB and find the specific endometrial pathology according to different bleeding pattern and clinical features.

\section{METHODS}

This retrospective study was done on patients presenting with AUB for last 6 months in perimenopausal age group at a gynecology clinic in a training and research hospital between January 2013 and January 2014. All women were evaluated through speculum examination in order to exclude bleeding from cervical lesion and cervical cytology was performed to all women. Serum pregnancy test was performed to exclude intrauterine or ectopic pregnancy. Complete blood count was obtained to look for anemia and thrombocytopenia. Serum human chorionic gonadotrophin (hCG), Follicle Stimulating Hormone (FSH), Luteinized Hormone (LH), estradiol $\left(\mathrm{E}_{2}\right)$, prolactin (PRL) and Thyroid Stimulating Hormone (TSH) concentration were measured in all patients. The patients were grouped according to clinical features, as menorrhagia (excessive or prolonged menstrual bleeding at regular intervals), metrorrhagia (light bleeding from the uterus at irregular intervals), menometrorrhagia (heavy bleeding from the uterus at irregular intervals), polymenorrhea (regular bleeding that occurs at an interval less than 21 days), and intermenstrual bleeding (intercycle spotting or bleeding).

Only the patients with isolated endometrial causes of abnormal uterine bleeding were included for the study and those with leiomyoma, cervical, vaginal pathology and patients with systemic disorders and using intrauterine device were excluded. Transvaginal ultrasonography was done and endometrial sampling was performed to all women. The endometrial sampling specimens were transported in $10 \%$ formalin to the pathology laboratory. The tissue bits were processed in automatic tissue processor and paraffin blocks were prepared. Tissue sections stained with hematoxylin and eosin stain. Histopathological results were classified as Proliferative Endometrium (PE), Secretory Endometrium (SE), Disordered Proliferative Pattern (DPP), Endometrial Polyp (EP), Chronic Endometritis (CE), Endometrial Hyperplasia (EH), Endometrial Adenocarcinoma (CA).

All data were analyzed using SPSS Statistics (SPSS, ver. 15.0, Chicago, IL, USA). Variables were reported as means \pm SD (Standard Deviation) and n $(\%)$. Differences between the groups were assessed using a $\chi^{2}$ test, Fisher's exact test. $\mathrm{P}<0.05$ was considered to indicate statistical significance.

\section{RESULTS}

The mean age of the patients was $44.4 \pm 4.3(40-52)$ years. The predominant endometrial histopathological pattern was PE+SE in $163(52.0 \%)$ patient of total 313 patients. DPP, EP, CE, EH with atypia and $\mathrm{EH}$ without atypia were seen in 30 (9.5\%), 37 (11.8\%), 33 (10.5\%), $42(13.4 \%)$ and $7(2.2 \%)$ patients, respectively. Only one patient had diagnosis of endometrial adenocarcinoma. Menorrhagia was the most frequent symptom 141 (45.0\%). Menometrorrhagia, metrorrhagia, polymenorrhea and intermenstrual bleeding were presented as $99(31.6 \%), 28(8.9 \%), 25(7.9 \%)$ and 20 $(6.3 \%)$, respectively.

Table 1: Distribution of histopathological findings according to abnormal uterine bleeding pattern.

\begin{tabular}{|lllllllll|}
\hline Type of bleeding pattern & Pathological findings $n(\%)$ & EP & CE & $\begin{array}{l}\text { HP w/o } \\
\text { atypia }\end{array}$ & $\begin{array}{l}\text { HP w/ } \\
\text { atypia }\end{array}$ & CA & P $\left(\chi^{2}\right)$ \\
\hline Menorrhagia $(\mathrm{n}=141)$ & $47(33.3)^{*}$ & $26(18.4)$ & $12(8.5)$ & $14(9.9)$ & $34(24.1)^{*}$ & $7(5.0)$ & $1(0.7)$ & $<0.001(72,402)$ \\
\hline Metrorrhagia $(\mathrm{n}=28)$ & $16(57.1)$ & - & $3(10.7)$ & $6(21.4)$ & $3(10.7)$ & - & - & $0.274(7,540)$ \\
\hline Menometrorrhagia $(\mathrm{n}=99)$ & $76(76.8)^{*}$ & $4(4.0)$ & $12(12.1)$ & $4(4.0)$ & $3(3.0)$ & - & - & $<0.001(42,760)$ \\
\hline Polymenorrhea $(\mathrm{n}=25)$ & $22(88.0)^{*}$ & - & $1(4.0)$ & $2(8.0)$ & - & - & - & $0.018(15,250)$ \\
\hline $\begin{array}{l}\text { Intermenstrual bleeding } \\
(\mathrm{n}=20)\end{array}$ & $2(10.0)$ & - & $9(45.0)^{*}$ & $7(35.0)^{*}$ & $2(10.0)$ & - & - & $<0.001(42,061)$ \\
\hline
\end{tabular}

*A statistically significant higher rate than others in histopathologic findings (in same bleeding pattern group). Data are given as n (\%).

- PE+SE, Proliferative endometrium + Secretory endometrium; DPP, Disordered proliferative pattern; EP, Endometrial polyp; CE, Chronic endometritis; HP, Endometrial hyperplasia; w/o, Without; w/, With; CA, Endometrial adenocarcinoma 
PE+SE and endometrial hyperplasia without hyperplasia were significantly more found in patients with menorrhagia symptom ( $\mathrm{P}<0.001)$. The most common histopathological finding was $\mathrm{PE}+\mathrm{SE}$ in patients with menometrorrhagia and polymenorrhea symptom (P $<0.05)$. There was no statistically significant difference between other histopathological results with menorrhagia, menometrorrhagia and polymenorrhea. EP and CE were significantly more observed in endometrial specimens of patients with complaint of intermenstrual bleeding $(p<0.001)$. However, no significant difference was determined between metrorrhagia and endometrial histopathological findings $(\mathrm{P}>0.05)$ (Table 1).

\section{DISCUSSION}

AUB is a nonspecific and general term that means bleeding that is excessive or occurs outside of normal cyclic menstruation. In clinical practice, the diagnosis depends on patient perception of their own "normal" or "abnormal" bleeding in terms of quantity, duration, and frequency, and if it is affecting the patient's quality of life. ${ }^{8}$ Majority of cases are seen after menarche or in the perimenopausal period. ${ }^{9}$ Although a detailed history with pelvic examination, blood tests, and transvaginal ultrasonography, the cause of bleeding can only be established approximately in $50-60 \%$ of the cases. ${ }^{3}$

The patient can have variety of abnormal menstrual patterns in perimenopausal age group and seek treatment. Menorrhagia is generally accepted as most common clinical presentation of AUB and defined as heavy menstrual bleeding loss that interferes with the woman's quality of life. ${ }^{10}$ Approximately two-thirds of naturally menstruating women aged 40-54 years reported heavy menstrual bleeding in the previous 6 months. ${ }^{11}$ In our study, menorrhagia was predominant complaint, and menorrhagia group accounted for $45 \%$ of patients. We also found that $\mathrm{PE}+\mathrm{SE}$ and $\mathrm{EH}$ without hyperplasia were significantly more common than the other histopathological findings in patients with menorrhagia complaint. Although menorrhagia is the most common presentation of AUB in perimenopausal age group, in a study a high incidence rate of resolution of heavy menstrual bleeding during the perimenopausal years is also found. ${ }^{11}$ The high rate of resolution of menorrhagia in perimenopausal years is important when giving information and planning treatment of these patients.

Our study showed that majority of endometrium specimens were related to normal physiologic menstrual phases as PE+SE in $163(52.0 \%)$ cases. Similar results were found in the other studies. ${ }^{12-14}$ On the other hand, DPP refers abnormal proliferative phase of endometrium but abnormality is not enough to be considered hyperplastic and like focal hyperplasia rather than diffuse. $^{15}$ In this study, $9.5 \%$ of 313 cases showed disordered proliferative pattern.
The incidence of $\mathrm{EH}$ in premenopausal women is reported to be $2 \%$ to $10 \%$. ${ }^{16,17}$ In most studies, also $10 \%$ to $20 \%$ of cases of endometrial cancer occur before menopause. $^{18,19}$ As EH is thought to be precursor of endometrial carcinoma, the diagnosis and treatment is important so perimenopausal women with heavy or irregular menstrual bleeding are often advised to have an endometrial sample taken to exclude endometrial disease. $^{20}$ The sensitivity of endometrial biopsy for the detection of endometrial abnormalities has been reported to be as high as $96 \% .^{21}$ The incidence of $\mathrm{EH}$ without atypia was $13.4 \%$ and $2.2 \%$ with atypia in this study comparable to other studies. ${ }^{16,18,20}$ Endometrial polyps are one of the endometrial pathology that can cause abnormal uterine bleeding in women. ${ }^{22}$ The prevalence of EP is found to be 10 to 24 percent in endometrial biopsy or hysterectomy specimens. ${ }^{23,24}$ In our study 37 (11.8\%) cases were diagnosed as EP. Polyps can be missed in in curettage specimens and seen as polypoidal fragments in specimens. In our study, EP was significantly more than the other histopathological findings among patients presenting with intermenstrual bleeding. Chronic endometritis can also be a cause for AUB and detected in approximately $8.0 \%$ of endometrial specimens. ${ }^{25}$ Women with symptomatic CE may present with AUB like intermenstrual bleeding, spotting, postcoital bleeding, menorrhagia, or amenorrhea with normal pelvic examination. Although organisms like Chlamydia, Tuberculosis, Neisseria, group B Streptococcus, mycoplasma and many viruses can be responsible for non-specific inflammation of the endometrium, in as many as one-third of these patients there is no apparent etiology. ${ }^{26}$ In our study, $10.5 \%$ of patients was diagnosed as $\mathrm{CE}$, and intermenstrual bleeding was statistically related with $\mathrm{CE}$. It is important to diagnose $\mathrm{CE}$ in these women because with appropriate antimicrobial therapy, the symptoms of the patients improve. ${ }^{27}$

According to our knowledge, this is a preliminary study to evaluate the correlation of menstrual bleeding pattern on abnormal endometrial histopathological findings in perimenopausal women. We concluded that menorrhagia and intermenstrual bleeding are mostly correlated with abnormal endometrial histopathological findings. Clinicians should give attention for these abnormal bleeding patterns to not to delay the evaluation of endometrium. But it is necessary to be studied in different cohort groups with larger populations.

\section{Funding: No funding sources Conflict of interest: None declared \\ Ethical approval: The study was approved by the institutional ethics committee}

\section{REFERENCES}

1. Albers JR, Hull SK, Wesley RM. Abnormal uterine bleeding. Am Fam Physician. 2004;69:1915-26.

2. Sweet MG, Schmidt-Dalton TA, Weiss PM, Madsen KP. Evaluation and management of abnormal uterine 
bleeding in premenopausal women. Am Fam Physician. 2012;85:35-43.

3. Kotdawala P, Kotdawala S, Nagar N. Evaluation of endometrium in peri-menopausal abnormal uterine bleeding. J Midlife Health. 2013;4:16-21.

4. Heller DS. Pathologic basis for abnormal uterine bleeding with organic uterine pathologies. Menopause. 2011;18:412-5.

5. Barut A, Barut F, Arikan I, Harma M, Harma MI, Ozmen Bayar. Comparison of the histopathological diagnoses of preoperative dilatation and curettage and hysterectomy specimens. J Obstet Gynaecol Res. 2012;38:16-22.

6. Wren BG. Dysfunctional uterine bleeding. Aust Fam Physician. 1998;27:371-7.

7. Fraser IS, Critchley HO, Munro MG. A process designed to lead international agreement on terminologies and definitions used describe abnormalities of menstrual bleeding. Fertil Steril. 2007;87:466-76.

8. Ming C, Steven R. Goldstein. Office diagnosis and management of abnormal uterine bleeding. Clin Obstet Gynecol. 2012;55:635-50.

9. Awwad JT, Toth TL, Schiff I. Abnormal uterine bleeding in the perimenopause. Int $\mathbf{J}$ Fertil. 1993;38:261-9.

10. Fraser IS, Critchley HO, Broder M, Munro MG. The FIGO recommendations on terminologies and definitions for normal and abnormal uterine bleeding. Semin Reprod Med. 2011;29:383-90.

11. Shapley M, Blagojevic M, Jordan KP, Croft PR. The spontaneous resolution of heavy menstrual bleeding in the perimenopausal years. BJOG. 2012;119:54553.

12. Spencer CP, Whitehead MI. Endometrial assessment revisited. Br J Obstet Gynaecol. 1999;106:623-32.

13. Saraswathi D, Thanka J, Shalinee R, Aarthi R, Jaya V, Kumar PV. A study of endometrial pathology in abnormal uterine bleeding. J Obstet Gynecol India. 2011;61:426-30.

14. Jetley S, Rana S, Jairajpuri ZS. Morphological spectrum of endometrial pathology in middle-aged women with atypical uterine bleeding: a study of 219 cases. J Midlife Health. 2013;4:216-20.

15. Steven SG. Problems in the differential diagnosis of endometrial hyperplasia and carcinoma. Mod Pathol. 2000;13:309-27.

16. Ash SJ, Farrell SA, Flowerden G. Endometrial biopsy in DUB. J Reprod Med. 1996;41:892-6.
17. Vercellini P, Cortesi I, Oldani S, Moschetta M, De Giorgi O, Crosignani PG. The role of transvaginal ultrasonography and outpatient diagnostic hysteroscopy in the evaluation of patients with menorrhagia. Hum Reprod. 1997;12:1768-71.

18. Gallup DG, Stock RJ. Adenocarcinoma of the endometrium in women 40 years of age or younger. Obstet Gynecol. 1984;64:417-20.

19. Jeffrey JD, Taylor R, Robertson DI, Stuart GC. Endometrial carcinoma occurring in patients under the age of 45 years. Am J Obstet Gynecol. 1987; 1256:366-70.

20. Farquhar CM, Lethaby A, Sowter M, Verry J, Baranyai J. An evaluation of risk factors for endometrial hyperplasia in premenopausal women with abnormal menstrual bleeding. Am J Obstet Gynecol. 1999;181:525-9.

21. Litta P, Merlin F, Saccardi C, Pozzan C, Sacco G, Fracas M, et al. Role of hysteroscopy with endometrial biopsy to rule out endometrial cancer in postmenopausal women with abnormal uterine bleeding. Maturitas. 2005;50:117-23.

22. Lieng M, Istre O, Qvigstad E. Treatment of endometrial polyps: a systematic review. Acta Obstet Gynecol Scand. 2010;89:992-1002.

23. Van Bogaert LJ. Clinicopathologic findings in endometrial polyps. Obstet Gynecol. 1988;71:771-3.

24. Epstein E, Ramirez A, Skoog L, Valentin L. Dilatation and curettage fails to detect most focal lesions in the uterine cavity in women with postmenopausal bleeding. Acta Obstet Gynecol Scand. 2001;80:1131-6.

25. Mechels TC. Chronic endometritis. Am Fam Physician. 1995;52:217-22.

26. Vasudeva K, Thrasher TV, Richart RM. Chronic endometritis: a clinical and electron microscopic study. Am J Obstet Gynecol. 1972;112:749-58.

27. Eckert LO, Thwin SS, Hillier SL, Kiviat NB, Eschenbach DA. The antimicrobial treatment of subacute endometritis: a proof of concept study. Am J Obstet Gynecol. 2004;190:305-13.

28. Livingstone M, Fraser IS. Mechanisms of abnormal uterine bleeding. Hum Reprod Update. 2002;8:60-7.

DOI: 10.18203/2320-1770.ijrcog20150001

Cite this article as: Yilmaz Z, Yilmaz Akkas E,

Cakmak B, Gultekin IB, Karsli MF, Cekmez Y, Kara

OF, Kucukozkan T. Correlation of bleeding pattern

with endometrial histopathologic results in

perimenopausal women with abnormal uterine

bleeding. Int J Reprod Contracept Obstet Gynecol

2015;4:247-50. 